\title{
Racing for What? Anticipation and Acceleration in the Work and Career Practices of Academic Life Science Postdocs
}

\author{
Ruth Müller
}

\section{Key words:}

academic career;

life sciences;

postdocs;

anticipation;

acceleration;

individualization;

entrepreneurial

self; slow science;

qualitative

interviews; higher

education policy;

science \&

technology policy

\begin{abstract}
In the wake of contemporary new public management, the temporalities of academic work have undergone significant transformations. One key feature of these changes is a perceived acceleration of working pace. While this phenomenon is widely acknowledged in scholarship about the transforming universities, to date there are only few studies investigating its empirical details.

Building on qualitative interviews with 38 postdoctoral life scientists in Austria, this article investigates how these researchers experience the temporalities of their work and career practices. Postdocs are particularly susceptible to the changing demands of academic work life, as they mostly inhabit fragile institutional positions while they aspire to establish themselves in academia. The experience of being in a highly competitive race that requires a continuously accelerating working pace as well as a strong focus on individual achievement is central to their narratives about working for a career in academia. Drawing on recent scholarship on anticipation (ADAMS, MURPHY \& CLARKE, 2009), acceleration (ROSA, 2003) and the entrepreneurial self (BRÖCKLING, 2007), I develop the concepts of anticipatory acceleration and latent individualization to analytically capture postdocs' experiences of temporalities in the context of their work and career practices. In conclusion I discuss the possible impacts of these particular temporal orientations for the contents and formats of academic knowledge production and ask in how far concepts and movements such as "slow science" help to address effects and problems of these specific forms of acceleration and anticipation.
\end{abstract}

\section{Table of Contents}

1. Introduction

2. Theoretical Perspectives: Anticipation, Acceleration and the Entrepreneurial Self

3. Material and Methods

4. Empirical Findings

4.1 Academic careers as linear and exclusive trajectories

4.2 The postdoc period: Competing for a group leader position by increasing the impact per time ratio

$\underline{4.3}$ Epistemic consequences: Working in a state of anticipatory acceleration

4.4 Social consequences: Working in a state of latent individualization

4.5 A note on postdocs and their relation to local societal contexts

5. Conclusions: What Are We Racing For?

Acknowledgments

References

Author

Citation 


\section{Introduction}

In contemporary research cultures, as in industrialized societies in general, it often goes unquestioned that fast is always better (ADAM, 2003). Alas, who could object to more knowledge in a shorter period of time? Narratives about science's indispensable role in society are often narratives about urgent necessity: we need to understand more in order to cure, prevent, construct, excel, survive.

Particularly today, as ever more pressing global challenges such as climate change, rapid loss of ecological diversity and an economic downturn seem to demand instantaneous response, swift scientific progress is often portrayed as the only possible answer. Prime examples for this rhetoric include e.g. contemporary European Union science policy documents such as Horizon 2020 (EUROPEAN COMMISSION, 2011). Yet, at the same time, some voices in academia are questioning whether more speed in research will actually help us to get where we want to be going. Academia, they argue, is already dominated by a culture of speed that would produce growing heaps of publications, but would also marginalize time for slow creative thought and reflection. The proponents of "slow science" worry that science operating under the conditions of constant acceleration might move fast, but rather headlessly and hence not necessarily towards the right goals. "Bear with us, while we think," the authors of The Slow Science Manifesto (2010) urge their audience, emphasizing the necessity of slow and thorough thought about goals, means and processes for the beneficial advance of science. The Slow University initiative that is the background for this special section (O'NEILL, 2014a, and 2014b in this section) takes up this plea for slow and wants to think through what a focus on slow could entail for the organization of contemporary universities. [1]

My interest in slow science is academic and personal. It builds on my research about how career structures and working conditions in academia affect the knowledge production practices of scientists in the life sciences, and more recently the climate sciences. I first started experimenting with the term "slow science" in 2010, in conversations with Jenny REARDON, Jake METCALF, and Martha KENNEY at the Science \& Justice Research Centre, UC Santa Cruz. While the term seems to have emerged rather simultaneously in different national and intellectual contexts around that time (McCABE, 2012), in our context we remember it being coined, rather playfully and casually in conversation, by feminist science studies scholar Donna HARAWAY, as a possible antidote to the frenzy of speed in contemporary academia. While the term slow science can embrace many things, which is both a strength and a weakness, in the context of my work it serves as shorthand for imaginaries about a counter culture to the current fast-paced, metric-oriented research worlds I encountered in my research. Cultures that appear to worship and reward competition, mobility, individualism and speed above all else; that exhibit, as Barbara ADAM put it, "speed fetishism" (2003, p.101). [2]

To date, there is a rich corpus of work discussing the multitude of changes academic institutions have been undergoing in the wake of what is mostly summarized as "new public management" (NPM) transformations during, 
depending on national context, the last two to three decades (e.g. DEEM, 1998; FELT, 2009; FERLIE, MUSSELIN \& ANDRESANI, 2008; JACOB \& HELLSTRÖM, 2000; SLAUGHTER \& LESLIE, 1997). Central to virtually all changes instigated by the market-oriented management techniques of NPM is the introduction of a pervasive focus on efficiency and competition into almost all areas of academic work. Throughout the literature, increasing time pressures, the fragmentation of time into projects and work-packages, and a general sense of too little time for thorough thought is pointed to as among the consequence of this refocusing. Yet, only a few studies have explored the empirical details of these perceived shifts in the temporalities of academic work. Scholars who have, such as YLIJOKI and MÄNTYLÄ (2003), suggest that investigating what they call an emerging new (academic) "time consciousness" (HASSARD, 1991) may be central to understanding the social and epistemic consequences of NPM transformations for academia more broadly. [3]

A key feature of the changes, which all of the rather few studies of temporality in contemporary academic work ascertain, is an increase in experienced tempo of academic work, and a continuous demand to further speed up that already accelerated pace (GARFORTH \& CERVINKOVÁ, 2009; VOSTAL, 2014; YLIOJOKI \& MÄNTYLÄ, 2003). In the context of contemporary academic NPM inspired audit cultures (POWER, 1997; STRATHERN, 2000) accelerated pace of academic work refers to an increase of countable academic output per predefined unit of time, e.g. per year, such as data produced, articles written, volumes edited, grant proposals submitted, lectures given, students passed, etc. While quality of output is certainly still an important issue, in contemporary universities the question of quantity, of "How much countable output per unit of time?" is becoming an increasingly important assessment criterion, particularly in processes such as hiring or promotion of scholars. [4]

VOSTAL (2014) proposes that junior scholars, who often work on temporary contracts and aim at establishing themselves in academia, are particularly exposed to the demand to produce more units per time. "It seems that early career academics are particularly vulnerable to the restructuring of higher education in comparison with more established and tenured/permanently employed senior scholars and professoriate" (p.12f.). This includes a heightened vulnerability to the changing temporal frameworks of academic cultures. Similar to the differences between career stages, the focus on speed appears to be pronounced more or less strongly in different fields. While the imperative to "Speed up!" seems to interpellate a wide range of scholars across the disciplines and faculties, fast growing fields that are receiving high policy attention and investments, often due to hopes of economic return, and that are exhibiting high degrees of internationalization and competition appear to be particularly prone to processes of acceleration. One such field is the life sciences. GARFORTH and CERVINKOVÁ (2009) point out that scholars in this field are faced with a growing standardization of possible career trajectories in the context of increasing international competition. This would result in a "rigid, narrow and increasingly formalised career path [...] in the biosciences" (p.172) along which particularly junior scholars must run as fast as possible to outpace a growing number of 
known and unknown, local and international competitors. The article at hand focuses on a distinct category of junior scholars ${ }^{1}$ in the life sciences that are, as the empirical work shows, particularly strongly affected by experiences of competition and hence acceleration: postdoctoral researchers. [5]

Building on qualitative interviews with 38 life science postdocs in Austria, the article investigates how postdocs experience the temporal dimensions of their work and their careers. Questions of pace, of how fast one can and needs to work; the experience of being in a competitive race and questions of possible futures within and beyond this race will be central to these narratives. I will discuss a number of social and epistemic consequences of working in a race-like situation, e.g. regarding the social structure of life science labs, the design and organization of research projects and the life of postdocs beyond the lab. In conclusion I will reflect on how racing for a career in the life sciences relates to other goals traditionally associated with scientific inquiry, such as developing a greater basic understanding of the animated and unanimated world and creating societally relevant knowledge and practical problem solutions. [6]

\section{Theoretical Perspectives: Anticipation, Acceleration and the Entrepreneurial Self}

To lay the groundwork for making sense of the distinct temporal experiences of life science postdocs elaborated in the empirical analysis, I will now discuss a number of important concepts from the sociology of time and social theory that explore and theorize distinctive, overarching features of time and temporality in contemporary (Western) society. These are mainly ADAMS et al.'s (2009) work on anticipation as form of contemporary governance; Hartmut ROSA's (2003, $2005)$ reflections on acceleration as a pervasive societal mode of operation and experience; and Ulrich BRÖCKLING's (2007) concept of the "entrepreneurial self" as form of self-governance under the conditions of neoliberal governmentality and omnipresent competition. [7]

In a 2009 paper on anticipation as a mode of governance, ADAMS et al. argue that "one defining quality of our current moment is its characteristic state of anticipation, of thinking and living toward the future" (p.246). They further elaborate:

"The present is governed, at almost every scale, as if the future is what matters most. [...] As an affective state, anticipation is not just a reaction, but a way of actively orienting oneself temporally. [...] Regimes of anticipation are distributed and extensive formations that interpellate, situate, attract and mobilize subjects individually and collectively" (p.248). [8]

In an age of growing uncertainty on many levels, anticipation as the attempt to make the future controllable through certain actions in the present becomes an ever more dominant mode of being in the world. The present increasingly

1 A rather vague, and in itself politically problematic container term, see PAIN (2014). 
becomes a resource to reach or avoid desired or dreaded futures. Imagined futures can induce highly affective states that govern individual and collective behaviors in the present. The making of certain futures often legitimizes a pervasive resourcification of the present. [9]

Yet, what is not part of these anticipatory calculations is that the present has a future life of its own that is often unexpected and goes beyond that which is anticipated, feared or desired. Lived presents are always more than resources to be translated into anticipated futures. They are complex social phenomena that pass on every detail of their existence in one or another way. ADAMS et al. (2009) argue that in the anticipatory mode, the present is often ignored-it is glossed over by the eye fixed on the future. However, it is exactly this inattentiveness and devaluation of lived presents that tend to sabotage even the most beautifully pictured futures. In his book "Seeing like a State: How Certain Schemes to Improve the Human Condition Have Failed," James C. SCOTT (1998) gives striking historical examples of how future-oriented projects have failed in the past-ranging from radical restructuring of farming practices in the Soviet Union or attempts to conjure a modern Brazil over night by means of modernist city planning. What all of these projects had in common is a certain disregard for the present: The present figured not as important in and of itself, but as valuable because of its potential to become the future. Discomfort and sacrifice in the present were hence normatively acceptable and reframed as potentially beneficial. If the present is only a moment of transition towards a golden future, no serious attention needs to be paid to the trials and tribulations of the now. Uneasiness with a new system is recast as a period of adaptation, critique is washed away with the final argument of where we need to go. SCOTT shows, how, with their eyes fixed on the future, the planners of the past cropped and mutilated the present, attempting to fit the complexities of human life into their schematic visions of the time to come. [10]

ADAMS et al. (2009) as well as SCOTT (1998) point to the modalities and effects of a pervasive orientation towards the future, and of anticipatory practices that think the present mainly in relation to and as a resource for certain futures. In the contemporary context, the overwhelming authority of the future over the present needs to be considered in relation to what Hartmut ROSA $(2003,2005)$ describes as a comprehensive acceleration of society. Anticipation as a mode of governing the self and others becomes dominant in a society that is, in general, considered to speed up. ROSA (2003) argues that there is evidence for three interrelated forms of acceleration taking place: technological acceleration (e.g. in transportation, communication, production); acceleration of social change (changes in social constellations and structures); and acceleration of the pace of life (increase in events/activities per time; an ethics of and desire for "do[ing] more things in less time" [p.9]). With growing rates of change, anticipating the future becomes ever more important. Indeed, ROSA argues, the present itself might even be shrinking in the context of an accelerating society and become less of a wide playing field than more of a narrow ridge between fleeing past and fast-approaching future, offering only little ground to stand on. Here ROSA draws 
on conceptualizations of past, future and present developed by philosopher Hermann LÜBBE (1998) and historian Reinhart KOSELLECK (1985). He writes

"Lübbe claims that Western societies experience what he calls the 'contraction of the present' (Gegenwartsschrumpfung) [...] For Lübbe, the past is defined as that which $[\ldots]$ is no longer valid while the future denotes that which [...] is not yet valid. The present, then, is the time-span for which (to use an idea developed by Reinhart Koselleck) the horizons of experience and expectation coincide. Only within these time-spans of relative stability can we draw on past experiences to orient our actions and infer conclusions from the past with regard to the future. Only within these timespans is there some certainty of orientation, evaluation, and expectation" (ROSA 2003, p.7). [11]

Under the conditions of comprehensive acceleration, the time spans in which expectation and experience coincide are becoming shorter and shorter. ROSA hence argues that social acceleration is both defined and made palpable "by an increase in the decay-rates of the reliability of experiences and expectations and by the contraction of the time-spans definable as the 'present'" (p.7). On individual as well as collective levels, the experience of a shrinking and fastdecaying present can in turn induce a stronger orientation towards the future; an anticipatory orientation that aims to create future possibilities and tentative certainties, and ensure an ongoing trajectory that is somewhat recognizable as a good (future) life. The resources this anticipatory mode of (self-) governance can put to use lie in the present: the shrinking present, whose currencies of today might be worthless tomorrow; and in the present selves that, like their time, might easily become obsolete and outdated, if they don't keep up with the times. [12]

This narrative about acceleration as sketched by ROSA, LÜBBE and others is implicitly-and sometimes explicitly_built on the assumption that the selves of the accelerating society exist in a condition of almost ubiquitous competition. Here, theories of social acceleration can be productively linked with scholarship on processes of subjectification in contemporary societies in the field of governmentality studies (BRÖCKLING, KRASSMANN \& LEMKE, 2000; BÜHRMANN 2005). With regard to the nexus of acceleration and competition, BRÖCKLING's $(2005,2007)$ work on the "entrepreneurial self" as an important mode of contemporary subjectification is particularly interesting. BRÖCKLING builds on the works of Michel FOUCAULT, who argued that neoliberal governmentality would increasingly produce subjects, who understand and conduct themselves as if they were entrepreneurs of themselves; "who [are their] own capital, [their] own producer, [their] own source of property" (2004, p.314). This entrepreneurial self emerges as form of self-governance and governance of the self in late modern societies, in which states take over less and less responsibilities for their citizens and employing institutions for their employees, but instead they appeal to them to take their lives into their own hands and make something of themselves on the free and open market of local and global opportunities. Inherent to this appeal is a strong temporal dimension, suggesting continuous self-improvement and adaptation to market needs and trends. The entrepreneurial self is, at most, only good enough for the already fading moment 
of the now, as the conditions, opportunities, exposures and perils it needs to exploit and master are already changing again. In that sense, the entrepreneurial self is less of a state of being than of becoming. As BRÖCKLING $(2005, p .12)$ writes, the entrepreneurial self

"[...] marks a direction for the way in which individuals are to change and be changed. It exists only in the gerund as something being produced and optimized. One is not an enterprising self, but is rather becoming one. Speaking of this self is never a description, but rather an interpellation." [13]

The entrepreneurial self is hence always on the run, becoming what it is supposed to already be. Under the conditions of acceleration and marketeconomic competition being an entrepreneurial self "implies being compelled to permanently achieve more [...] [b]ecause one can assert his position only for the moment and only in relation to his competitors [...]. Today's recipe for success is tomorrow's path to ruin" (p.15). Here we find a clear resonance with LÜBBE's and ROSA's diagnosis that the present as a point of reference and reliability is shrinking, and with ADAMS et al.'s conclusion that anticipation is becoming a pervasive mode of temporal orientation of contemporary subjects. The future in all its uncertainty is lurking and looming, and wants to be tamed by strategic, efficient and most of all prompt anticipatory action in the present. The shrinking space of the present that provides momentary orientation and congruency of expectations and experiences needs to be put to good use to prepare as best as possible for a future that cannot be known, but must be anticipated, and is sure to come. [14]

In the empirical part of this article, I will show how life science postdocs in Austria can, as they are trying to build a career in academia, be understood as entrepreneurial selves that operate significantly in a mode of future-orientation that can be sketched as first, anticipatory acceleration and second, latent individualization. I will draw out social and empirical consequences of these modes of self-governance, and in conclusion discuss these in connection to other, more societal than individual, hopes and expectations projected onto scientific research. [15]

\section{Material and Methods}

For its analysis, the article draws on 38 interviews with postdoctoral life scientists, conducted between 2007 and 2013, as its main material. 21 of these interviews ${ }^{2}$ have been conducted in the course of the ELSA ${ }^{3}$-research project "Living Changes in the Life Sciences. Tracing the 'ethical' and 'social' in scientific

2 This number includes 16 postdocs working as group member scientists, 2 postdocs with special fellowships that allowed them to have a small research group for themselves, and 3 researchers, who had not formally finished their $\mathrm{PhD}$ research at the moment of the interview, but were already focused on the postdoctoral academic labor market. The postdocs' ages ranged from their late twenties to their mid-forties, with the majority aged between 30 and 35 . With one exception, all aimed at succeeding in an academic career, with the goal of becoming an established senior scientist (group leader, professor, research director).

3 Elsa = "Ethical, Legal and Social Aspects of Science." 
practice and work culture"4 in 2008 and 2009. This project investigated how changes in the framework conditions of life science research-such as changes in funding structures, increasing projectification of scientific work and the integration of multiple audit mechanisms - are reflected and negotiated within the work cultures and research practices of life scientists in Austria. The core methodological approach of this project consists of biography-oriented, semistructured interviews with life scientists. The sample included life scientists from different sub-fields (biomedical, plant biotech, microbial, bioinformatics) and different career stages (PhD students, postdocs, research group leaders). The project team always interviewed several researchers within one lab, starting with the group leader. Labs of interest were identified through interviews with the seven members of project's life science advisory network. These interviews were conducted at the beginning of the project in order to map the Austrian life science landscape. [16]

Each interview was about 2-3 hours in length and consisted of three main parts: a first part aimed to evoke a biographical narrative about the researchers' ways into science up to their current position and about their possible future paths; a second part focused on their current research practices, discussing both their social and their epistemic dimensions; and a final part invited the interviewees to discuss certain buzz words in science policy, such as excellence, mobility, societal relevance, etc., and their concrete meaning within their everyday work and live as life science scholars. As the interviews encouraged reflection regarding the interplay between policy, institutional structures and personal experience/practice, and constituted, among other things, a conversation between academic peers, the project team named them "reflexive peer-to-peer interviews." A more detailed discussion of this methodological approach can be found in FELT, FOCHLER and STRASSNIG (2010) and in MÜLLER and KENNEY (2014). [17]

Beyond the 21 interviews with postdocs conducted in the initial study, the article draws on two additional group interviews with four life science postdocs conducted during research stays in the United States in 2010 and 2011. These group interviews followed an adapted version of the one-to-one interview guideline for the reflexive peer-to-peer interview. The article is further informed by interviews with 17 life science postdocs in an Austrian postdoc-excellenceprogram conducted in a study in $2013^{5}$ that followed a context sensitive variation of the initial interview guideline. [18]

The key focus of my analysis as part of the initial project and in the follow-up research was how values, norms and structures of making a career in academia affect researchers' working practices. Postdocs are a particularly interesting group of researchers for exploring these questions. The increasing prominence of

4 Conducted from September 2007 to December 2010 at the Department of Science and Technology Studies, University of Vienna, Austria. The project was funded by the Austrian Genome Program GEN-AU; project leader: Prof. Ulrike FELT; main collaborators: Maximilian FOCHLER and Ruth MÜLLER.

5 VIPS (Vienna International Postdoc Program) Impact Assessment Study, funded by VIPS from May to June 2013. 
this rather new type of scholar is in itself a symptom of changing patterns of organizing academic work, lives and careers. Today, significantly more people are acquiring a $\mathrm{PhD}$, particularly in fields of policy interest and investment such as the life sciences, and aim for an academic career, but compared to these numbers, there are far less senior positions available (BENDERLY, 2005). Hence, an increasing number of people are working as postdoctoral researchers for an increasing number of years, a status that is often loosely defined as being an academically employed researcher holding a $\mathrm{PhD}$, but not a senior or faculty position. Postdocs are typically employed on short-term contracts (1-3 years). A high degree of international mobility is usually characteristic for this period of academic work, caused by both pull factors (the attractiveness of certain international research institutions) and push factors (not enough positions available in the home country; going abroad as a norm and value of career development; see ACKERS, 2008). Competition and career pressures, particularly in terms of expected research productivity and publication output, are high during these years, and chances of transitioning into more stable, senior academic employment are at best uncertain, if not plain slim. [19]

Hence, precariously located at this narrowest "bottleneck" (RUSSO, 2003) of contemporary scientific careers, postdocs' accounts offer dense narratives about how contemporary career rationales influence their ways of working and living in life science research. I analyzed this nexus with a grounded theory based approach, with multiple consecutive rounds of coding and analysis (CHARMAZ, 2006; STRAUSS \& CORBIN 1998). ${ }^{6}$ This article draws together those aspects of the analysis, in which questions of temporality and particularly acceleration of work pace figure prominently. I further incorporate relevant analyses and arguments from the published work of two colleagues (Ulrike FELT, Maximilian FOCHLER), with whom I collaborated in the initial research project "Living Changes in the Life Sciences". [20]

\section{Empirical Findings}

In this empirical section, I will develop two main arguments about life science postdocs' temporal orientations. The first is that under the conditions of current largely metric-based and internationalized academic competition, postdoctoral life scientists adopt a set of future-oriented behaviors that I will subsume under the notion of anticipatory acceleration. Second, I will argue that in relation to anticipatory acceleration postdocs' social relations in and to life science research groups and institutions are shaped by a state of latent individualization ${ }^{7}$. Throughout the section, I will be understanding postdoctoral subjectivities as distinctive context-dependent instantiation of the contemporary form of

6 In the initial rounds of open coding the nexus of career considerations and postdocs' working and living practices emerged as a key theme that became the topic of my research work between 2008 and 2012. Within this broad topic, the relationship between individuality (e.g. individual career aspirations and trajectories) and collectivity (e.g. collective working contexts) became a focal point and sensitizing concept (BLUMER, 1954; BOWEN, 2006) for the following rounds of analysis.

7 I have first developed this analytical concept in a study on how postdocs engage in supervision work of PhD students (MÜLLER, 2014). 
subjectivation that BRÖCKLING $(2005,2007)$ describes as the entrepreneurial self. To give the reader a sense of the contexts in which both anticipatory acceleration and latent individualization emerge, I will start the section with a description of how postdocs perceive the trajectories and rationalities of contemporary academic life science careers, and of the specific role of the postdoc period within this career path. [21]

\subsection{Academic careers as linear and exclusive trajectories}

To understand postdocs' temporal orientations, it is crucial to first outline their understanding of what an academic career is or can be. First, as GARFORTH and CERVINKOVÁ (2009) elaborate to be the case for early career researchers in the life sciences in a number of European countries, postdocs in the life sciences in Austria have a highly standardized vision of what an academic career path looks like. After a PhD that should ideally be completed in 3-4 years (usually the timeframe of available funding) in either one's home country or abroad, an aspiring life science researcher will hold 1-2 consecutive international postdoc positions of 1-3 years each, preferably at prestigious institutions in Western European or North American countries, and then make the leap to becoming an independent junior group leader, and from there at some point to becoming a senior group leader. While this envisioned career track in itself might not be very surprising, it is important to note that, first, this is the only way postdocs think an academic career can be done. For example, taking breaks along this path, working in non-academic research or trying out a different, non-research career at some point, are all perceived as practically impossible deviations that would significantly diminish academic career chances. [22]

Second, it is important to note how this career path is normatively imagined as international. The postdocs interviewed in both studies this article draws on, no matter if they were born in Austria or came to Austria for academic employment, considered a career without significant periods of international mobility to be virtually impossible. Personal restrictions or reluctances to be internationally mobile were seen as severely hindering career prospects. This high degree of expected and experienced mobility is important to keep in mind for understanding how postdocs related to their current local working and living context. [23]

There is third important and distinctive feature of how the academic career path is perceived, that is yet less described in the literature: the academic career path is not only perceived as highly linear, but also as rendering those, who wander it, increasingly unfit for other careers. As junior scholars progress from PhD to postdoc, they increasingly assume that their particular training makes them fairly unattractive for non-academic employment. Comparing interviews with $\mathrm{PhD}$ students with postdoc interviews, the latter appear much more unsure of what they would have to offer to employers outside academia. ${ }^{8}$ Additionally, academic

8 This is not least a product of academic ways of measuring a person's worth. Hardly ever is a scholar's worth measured in abilities and skills, but rather only in units of output, a form of evaluation and self-evaluation that does not easily translate into private sector forms of assessing a possible employee's potentials. 
enculturation in the life sciences provides a mindset, in which academic work is normatively superior to other types of employment and hence leaving academia is considered a failure of either desire or capability. ${ }^{9}$ Even expressing interest in non-academic employment among peers or particularly towards superiors is considered to be potentially damaging to one's reputation as a serious scholar. Hence, other professional options beyond academia mostly remain unexplored and even unimagined. This means that in practice, postdocs' impressions of their future options are characterized by a relatively clear-cut, yet highly uncertain academic path standing out against a vague background of mostly undetermined other professional possibilities. Depending on personality type and particular subfield, this leads some postdocs to consider their job prospects beyond academia dull and unattractive, while others fear that there is not really anything for them out there, and that if they had to leave academia they might end up in long-term unemployment. Hardly any postdoc interviewed in the studies this article draws on considered their job prospects beyond academia good or exciting. [24]

\subsection{The postdoc period: Competing for a group leader position by increasing the impact per time ratio}

Along this linear, internationally mobile and exclusive academic career path, the postdoc period is considered to be of unique importance: it is envisioned to be the moment of highest selection in terms of people being selected out of the academic career, and hence assumed to be the time of the highest competition along the track. This perspective is not only brought forward by postdocs themselves, but also echoed in the interviews with PhD students and research group leaders in the initial study, as well as in discussion pieces in key scientific media such as BENDERLY (2005) or RUSSO (2003). In this mindset, the postdoc period becomes primarily a time-space that needs to be successfully traversed. [25]

This makes the postdoc significantly different from the PhD period (FOCHLER, FELT \& MÜLLER, 2014/forthcoming). Doing a PhD is seen as an aim in itself that might give rise to an academic career, but still possibly also to other professional trajectories. Life Science PhD students in our study also hardly feared that they might fail to complete the $\mathrm{PhD}$; it might take a bit longer than expected or ideal, but their supervisors would ensure that they would ultimately have enough academic capital in terms of data and results to pass. Doing a postdoc on the other hand is hardly seen as an aim in itself and its completion-the transition to the research group leader stage-is considered to be highly uncertain. The possibility of this transition is perceived to depend on acquired academic capital per time, not on academic capital per se. A PhD can be extended and still passed with the same amount of capital, but as time moves on in an extended postdoc

9 It is interesting to note that postdocs appear to often lose sight of peers, who have left academia: what those people might be doing now remains often a mystery to academic postdocs. This situation has, for example, led postdoc representatives at the renowned European Molecular Biology Organization (EMBO), to actively invite former postdocs, who are now pursuing non-academic careers, to come back and give talks about their work so current postdocs could develop ideas of what else they could do. 
period, the increment in capital needs to be rather steep to make up for the additional time. Moreover, in times of increasing competition standards of what counts as possibly enough capital for the transition might rise as time passes, and catching up might also mean catching up to already again elevated expectations. Finally, there are perceived cut-off points in terms of age for transitioning from the postdoc to the group leader stage: 35 is often considered the age at which one should have made the transition. Someone, who is a postdoc at or after the age 40 , is suspicious in and of him/herself, because that "is somehow a sign that this person is not very successful, is not motivated" (PDoc_1m 203 ${ }^{10}$ ). Hence, postdocs critically depend on and are attuned to the pace of their productivity: on how many units of output they can produce within what is perceived to be an acceptable time span of postdoc existence. [26]

What are these units of output? The answer is as simple as it might obvious: publications, or more precisely, impact factors of publications. Put bluntly, publishing at a (cumulative) high impact is the key goal of postdoctoral activity. This aim can be reached, often preferably, through one or a few publications of high impact each, or if this is not possible, through a higher number of publications at lower impact. While a publication in the big three of life sciences journals-Nature, Science or Cell-will go a long way to increase career prospects and high impact is generally aimed at, overall, it is the cumulative impact factor of a researcher's publications per unit of time that increasingly becomes the measure of his or her productivity and hence quality. As one postdoc put it (capturing in his speech pattern much of the breathlessness that often goes along with keeping this ratio up):

"You need to keep publishing papers, you need to publish, you need to make sure you publish papers over a year. If you don't have papers over a year then you are toast. [...] I need at least one, two papers a year [...] or one really good one every few years" (PDF_2m 1058), [27]

In postdocs' narratives, publication often is not longer something that possibly happens at the end of a research process that might take a number of years, but it rather becomes a continuous activity. Gaps in publication patterns come to indicate not periods of intense research, but rather inertia, lack of motivation or capability. Research processes hence need to be planned and staggered in ways that allows for a rather continuous flux of publications. Here the epistemic and social impacts of the demand to work at a high pace of output production start to become tangible. In the following two subsections, I will first discuss key epistemic consequences of this, and then crucial effects on the social organization of research labs. ${ }^{11}[28]$

10 This abbreviation depicts: career stage, interview number, gender and line in interview transcript.

11 Please bear in mind that the distinction between the epistemic and the social is somewhat artificial. Aspects of research work that are usually discussed as social (e.g. whether to work on a project individually or collaboratively) of course have effects on the epistemic level. In turn, issues usually addressed as epistemic (e.g. such as selecting a research question) can have impacts on the social structure of a lab (e.g. depending on how this question relates to what others in the lab work on). Yet, for clarifying that an increase in working pace does not only have 


\subsection{Epistemic consequences: Working in a state of anticipatory acceleration}

In this subsection, I will develop the notion of anticipatory acceleration to refer to the temporal orientation in which postdocs are making decisions about the epistemic content of their research. With regard to the overbearing question of publication output per time, question of epistemic risk, i.e. the predictability or openness of the outcomes of research processes, becomes paramount in these decision processes. I will use this discussion of risk and predictability to elaborate what is meant by anticipatory acceleration. [29]

Under the conditions described above, research processes tend to become foremost vehicles for the fast-paced production of publications. This is how one rather senior postdoc explained how she goes about developing her research projects:

"You already need to plan in the very beginning what papers you will be able to publish, which experiments do I need for that. It sounds way more calculating than you think when you naively start your research career. But you just have to focus on what's good for the papers" (PDoc_6f, 1319). ${ }^{12}$ [30]

The question of how to ensure regular publication output and avoid gaps in the publication record governs research process right from the start, influencing already the choice of a research question. Asked what the "ideal" postdoc project would look like this PhD student at the transition to becoming a postdoc answers:

"One that gives me a good paper in a year! [laughter] Well, you can never entirely cancel out all risks. But what I mean with 'risks' is how predictable it is what will come out of the research in a certain frame of time" (PhD_2m 971). [31]

Predictability of results and hence publication within a certain, foreseeable time span becomes a marker of an attractive postdoc project. Risk, in terms of less predictability and openness of possible results becomes problematic in a research culture, in which keeping up the relentless pace of publication is paramount. Epistemic risk needs to be avoided or at least tamed. ${ }^{13}$ Many postdocs employ the first strategy of choosing a rather safe project with somewhat predictable outcomes. Some postdocs, who speculate on a paper of particularly high impact (Science, Nature, Cell), attempt the latter: they work simultaneously on one safe and one high-risk project ${ }^{14}$. In the case of two postdocs in our interview sample, who had received a particularly generous fellowship from a leading Austrian research institution, working in such a twofold

social, but also epistemic impacts I chose to separate this categories for now.

12 This passage was also quoted in: MÜLLER and KENNEY (2014, p.545).

13 In this particular interview, the soon to be postdoc tells a narrative of ever declining possibilities to take risks along an academic career. Risk in his narrative is something only PhD students, who are allowed to operate in time-space that has less pressure to publish and more temporal freedom, can take. Senior scholars again can experience and engage with risk through their PhD students, while their postdocs need to be assigned rather safe questions and projects.

14 See SIGL (2012) for a detailed elaboration of different risk management strategies among earlycareer life science researchers. 
manner was even mandated. Attached to the high-risk project is the individual, and in the case of these two fellowships also the institutional, hope of achieving those groundbreaking results that allow for a publication in the big three, while the safe project shall guarantee a rather continuous flux of lower impact publications and hence provide a career fallback. Yet, as can be easily imagined, such a strategy requires exhaustively expanding working hours, often to and beyond postdocs' physical limits. This strategy is essentially a form of extensive multitasking, one of the phenomena ROSA (2003) describes as central to the acceleration of the pace of life. [32]

The parallelization of two, differently natured research endeavors as well as the initial example of focusing on one safe, fast to realize project during the postdoc are two examples of epistemic decision shaped what I shall term anticipatory acceleration. Postdoc accelerate their working practices, i.e. increase the amount of events per time, to their very limits not primarily because of concrete and timelimited time pressures (e.g. a person somewhere else in the world working on exactly the same topic; a specific deadline), but habitually and because of a profound anticipatory orientation that suggests that how ever much they are currently doing might not be enough and can still be optimized. Only research questions that can have a fit with this orientation or can be made to fit are considered possible choices. Inherently lengthy, speculative or highly unpredictable research projects can hardly be the sole focus of a postdoc researcher's attention under these conditions. [33]

The aim of postdocs' anticipatory acceleration is to make the future more controllable and to improve one's position the intense and threatening postdoctoral competition. Yet, as BRÖCKLING (2007) points out regarding such attempts of the entrepreneurial self to create some certainty, in the end no amount of effort can really overcome the fear of failure. Instead, the high investments and sacrifice weigh heavy on the postdocs. The long hours of work are shrinking their perspective on their future options ever more, resulting in a "vicious cycle" (PDoc_16f, 1052) of emotional dependency on and investment in academic success. Working in state of anticipatory acceleration shapes postdocs' research processes deeply, rendering epistemic decisions largely subject to the imperatives of this career-focused, anxious mode of anticipation that demands continuous acceleration. [34]

\subsection{Social consequences: Working in a state of latent individualization}

What does this imply for the social setting of the life science laboratory? Here, we need to remember that life science career trajectories are not only characterized by acceleration and anticipation, but also by international mobility. In most cases, the current laboratory hence figures mainly as a momentary stopping point along an internationalized, fast-paced career trajectory. Under the conditions of anticipatory acceleration everyday time is always scarce and desired to be devoted to those activities that can increase the output per time ratio. ROSA (2003) argues that processes of acceleration are often linked to conditions of 
individualization ${ }^{15}$, as the individual can accelerate more easily than the collective. In the case of life science postdocs this is reflected in a condition that I have described in an earlier article as a state of latent individualization (MÜLLER, 2014). The terminology of latent individualization tries to capture how postdocs' decision-making practices within their current institutions and groups are also almost always crucially shaped by considerations of and for a future self that is no longer part of it's current collective contexts. Latent describes the state of something not being there yet, but still, as a probable future, acting upon the present. In this case, it is postdocs' future selves who will have to prevail on the international academic labor market on their own, that become crucial reference points for postdocs' actions and decisions in the present. This specific anticipatory orientation towards their individual futures guides how postdocs' relate to the collective contexts of their presents. Institutions, groups and colleagues, become, despite the existence of and desire for emotional bonds such as friendships and loyalty, also and often foremost resources for their future scholarly survival. A research lab is only a good space to be in as long as it allows for ample and high quality results to be produced in a short period of time. A collaboration is only then desirable if it warrants publications of high impact or number in the next year or two. ${ }^{16}$ Supervising a student is only then advisable if chances are that the practice of advising will also produce co-authorships on the student's papers. The needs of the latent future self are decisively governing the present. [35]

Across the two studies, only a very small number of postdocs had any more longterm prospects at their current institutions. The prevalently nomadic postdocs' prime focus hence rested on how to translate as much of their work performed during their temporary engagements in a certain lab as possible into the quantitative, metric-based language of publication numbers and impact factors that dominates contemporary international academic labor markets. The question molding social relationships to and in research groups and institutions then becomes how these relations can be used to increase the ever decisive ratio of impact per time. At the end of a contract, the postdoc researcher must have reached escape velocity: that is enough impact per time to either transition to a group leader position or at least to another postdoctoral position that promises to be good enough to possibly allow for the desired transition to happen at the end of the next contract period. [36]

15 ROSA (2003) makes a more linear argument, suggesting that it is social acceleration that has created the phenomenon of individualization in modern societies (as described e.g. by BECK \& BECK-GERNSHEIM, 2002). I do not wish to take a stand in this ongoing debate, but while I agree that there is a link between both phenomena, I am inclined to consider the connection to rather a two-way than a one-way street.

16 See also MÜLLER (2012) on the nexus of career and collaboration in life science labs. 


\subsection{A note on postdocs and their relation to local societal contexts}

Needless to say, anticipatory acceleration and latent individualization also have effects on postdocs' lives beyond the lab. One aspect of this, which is less discussed than the more common issues of family life and child care, is how postdocs relate to the societal contexts they live in during periods abroad. Most postdocs will live in a country other than their home country at some point, for a number of years, possibly in a place where they don't speak the common language. FOCHLER (2010) argues that instead of creating a transnational, cosmopolitan research community that lives in and engages with different national contexts, international mobility as performed in current speed-fetishizing research cultures rather produces "cosmo-idiots": people, who travel but hardly get to know where they are; who move around the globe, but exist in a bubble of work and more work, without ever really engaging with local communities or the national political systems. In the Austrian case studies, young scholars frequently mentioned that they had no time to learn the local language, read the newspaper or engage in any political debates, even if these debates concerned science. This suggests that an increasing number of scholars per country are not actively participating in civil society, which, given the traditional role of academia as a source of critical thought and political activism, gives reason for concern. [37]

\section{Conclusions: What Are We Racing For?}

In this concluding section, I will briefly recap the concepts developed in this article to describe the temporal orientation of life science postdocs in their academic career making practices and the ways they are affecting the epistemic and social dimensions of their work. Then I will infer speculative conclusion about the broader contexts and impacts of these phenomena. [38]

Anticipatory acceleration is a type of acceleration that aims at increasing units of output per units of time that is not developed in response to a certain event or specific time horizon, but rather constitutes a generalized response to a state of pervasive competition in the academic life sciences that primarily selects along the question of "how much per time?." Anticipatory acceleration of this kind tends to privilege research questions and approaches that are predictable in terms of their outcomes, or requires highly elaborate and exhaustive individual risk management strategies to engage projects bearing more epistemic uncertainty, and hence potential for novelty. [39]

Latent individualization is a type of relation between the individual and its collective (working) contexts that emerges in life sciences laboratories under the condition of high international mobility, metric-based competition and respectively anticipatory acceleration. It indicates that researchers relate to their current collective contexts decisively through the perspective of the career needs of their future individual self that is no longer part of these contexts, but must prevail on the international academic labor market by itself. Latent individualization tends to render social relations to individuals, groups and institutions instrumental and tentative. [40] 
What can be inferred from the prevalence of these two interdependent temporal orientations in postdocs' accounts about their academic working practices? I offer speculative conclusions on two levels: the future of knowledge production; and the importance of the slow science movement. The first one concerns the question of which types of research cultures might be emerging with these temporal orientations, if one speculates that they are becoming increasingly pervasive. ADAMS et al. (2009) as well as SCOTT (1998) remind us that lived presents always also generate unexpected futures that go beyond those futures, which they have attempted to anticipate. FELT $(2013)^{17}$ captures this in her concept of "collateral futures" that she develops, inter alia, out of her studies of contemporary research cultures. These collateral futures have not been anticipated, but still they are materializing instead of or along-side the desired effects. In the case of the contemporary life sciences, and the ways in which they are currently temporally governed, what becomes apparent are the consequences of a pervasive focus on metrics-based competition enacted in science policy and institutional management for the research practices and the academic socialization of the coming generation of researchers. If researchers need to pass an increasing number of check-points at which the quality of their work and their scholarly biographies is inspected in terms of their productivity per time, researchers will develop social and epistemic habits that allow them to accommodate these demands. Extrapolating from the material at hand, this might mean a reduction of the complexity of problems addressed and a focus on meeting the outlined criteria of performance rather than on originality; it might also include an exhaustive focus on individual achievement and tendency towards the instrumentalization of others. The first could be a threat to academic inventiveness (OSBORNE, 2003; VOSTAL, 2014); the second to the social cohesion, collegiality and knowledge exchange in academic institutions. [41]

Here, we find a certain tension between expressed policy goals such as fostering original thought, collaboration and creative innovation, and the practice of attempting to achieve these goals through an ever increasing amount of metricbased competition. If for example science funders, on which academic are so increasingly dependent in their working life, regularly reject fellowships and grant proposals, because the curriculum vitae of the applicant does not show enough quality in terms of numbers and impacts of publications and citations counts, regardless of the content of the proposal, what does this say about the relationship between metrics and ideas in current science policy and administration? This is not to disavow quality control in academia, nor to suggest that performance metrics are generally useless. On the contrary, I find it of uttermost importance that academic institutions and funding bodies develop ways of actually assessing the quality that rests behind the few or many lines of a CV. The current pervasive focus on metrics-based competition however seems not to be the way to go, as this study and an emerging body of literature suggest. [42]

17 In developing this concept FELT draws on and adapts John LAW's (2011) concept of "collateral realities," introducing a focus on questions of temporalities and particularly future-making practices. 
What can be the place of the Slow Science movement or most recently the Slow University initiative within these debates about quality of academic work and the future of academic institutions? While other contributions in this special section and elsewhere criticize the term as conservative (MENDICK, this section), distracting from more analysis of cause and effect (MARTELL, this section) or plain toothless (VOSTAL, 2014) and suggest switching to a different, more complex vocabulary, I propose that if we do not only focus on the experiences and knowledge cultures of the social sciences and humanities, but take into account also natural science and engineering cultures, the term is useful because it speaks to the experiences of a broad variety of scholars across the fields. It is in that sense not necessarily satisfactory as an analytical category of social science research, but useful as a vector of intra- and inter-university mobilization. This is confirmed by the overwhelming interest in the two Slow University workshops at Durham University in 2013 and 2014 that gave rise to this special section. I think slow can serve as a sensible shorthand for relating critically within and to ongoing transformations in the university, because for scholars across the disciplines many of the problematic trends in current academia become tangible on the experiential level as questions of pace: as experiences of and demands for acceleration; as tensions between fragmentation of time, time pressures and creative and thorough academic practice; and as the demand to be an anticipating, flexible entrepreneurial self that is always a step ahead of its time in order to succeed in the pyramid scheme ${ }^{18}$ of academic careers. Slow, in the way in which it is used in the Slow Science movement and the Slow University initiative, and before that in the Slow Food or Slow Cities movements, understands slowing down as form of instigating a critical reflection on the values that are encompassed by the often unmarked fast. Starting a discussion about slowing down in academia in this sense is hence not necessarily to address the root of the problem, but can be a useful means to invoke and unpack the experiences of many scholars in different disciplinary contexts, and relate and rally across the divisions to develop models of resistance and change. It could lead to asking the question of Cui bono currimus ${ }^{19}$-To whose benefit is it that we are racing? Is it primarily to our own, in terms of our careers? To that of science? The economy? The public good? Answers to these questions and their alternatives can of course only form tentatively, and will possibly bristle with cynicism at first. Yet, this just shows that it is time to pose the question. [43]

18 Pyramid scheme (in German: ["Pyramidenspiel"): A fraudulent investment scheme in which new investors are attracted to the operation by promising unrealistically high returns for their investments after a certain amount of time. The scheme depends on a constantly growing number of new investors on the base of a pyramid structure, whose invested capital is transferred to those on top of the pyramid. New members are encouraged to attracted new investors themselves, so they can move towards the top of the pyramid.

19 Feminist science studies scholar Susan Leigh STAR (e.g. 1995), a relentless explorer and critic of the seemingly given and self-evident reminds us throughout her life's work never to forget to pose the question: Cui bono? To whose benefit? 


\section{Acknowledgments}

This article is based on research conducted in the research project "Living Changes in the Life Sciences," funded by GEN-AU/BMWF (Project leader: Ulrike FELT; main collaborators: Maximilian FOCHLER, Ruth MÜLLER; September 2007 to December 2010); and on research conducted in the course of the study "VIPS Impact Assessment Study" (May to June 2013), funded by the Vienna International Postdoc Program, Vienna Biocenter. Many thanks to Maximilian FOCHLER, Cornelia SCHADLER, Kay FELDER, Thomas VÖLKER and Maggie O'NEILL for their comments and feedback to earlier versions of this article. An initial outline of the article was first presented at the workshop "The Slow University?," Durham University, November 6, 2013. Thank you, Maggie, for taking the initiative and bringing us all together.

\section{References}

Ackers, Louise (2008). Internationalisation, mobility and metrics: A new form of indirect discrimination? Minerva, 46 (4), 411-435.

Adam, Barbara (2003). When time is money: Contested rationalities of time in the theory and practice of work. Theoria, 50(102), 94-125.

Adams, Vicanne; Murphy, Michelle \& Clarke, Adele (2009). Anticipation: Technoscience, life, affect, temporality. Subjectivity, 28(1), 246-265.

Beck, Ulrich \& Beck-Gernsheim, Elisabeth (2002). Individualization: Institutionalized individualism and its social and political consequences. London: Sage

Benderly, Beryl Lieff (2005). Not your father's postdoc. Editorial feature. Science, 308(5722), 717718.

Blumer, Herbert (1954). What is wrong with social theory? American Sociological Review, 18(1), 310.

Bowen, Glenn A. (2006). Grounded theory and sensitizing concepts. International Journal of Qualitative Methods, 5(3), 1-9.

Bröckling, Ulrich (2005). Gendering the enterprising self. Subjectification programs and gender differences in guides to success. Distinktion: Scandinavian Journal of Social Theory, 6(2), 7-25.

Bröckling, Ulrich (2007). Das unternehmerische Selbst: Soziologie einer Subjektivierungsform. Frankfurt/M.: Suhrkamp.

Bröckling, Ulrich; Krassmann, Susanne \& Lemke, Thomas (Eds.) (2000). Gouvernementalität der Gegenwart. Frankfurt/M.: Suhrkamp.

Bührmann, Andrea D. (2005) The emerging of the entrepreneurial self and it's contemporary hegemonic status: Some fundamental observations for an analysis of the (trans-) formational process of modern forms of subjectivation. Forum Qualitative Sozialforschung / Forum: Qualitative Social Research, 6(1), Art. 16, http://nbn-resolving.de/urn:nbn:de:0114-fqs0501165 [Accessed: September 19, 2014].

Charmaz, Kathy (2006). Constructing grounded theory. A practical guide for qualitative analysis. London: Sage.

Deem, Rosemary (1998). "New managerialism" and higher education: The management of performances and cultures in universities in the United Kingdom. International Studies in Sociology of Education, 8(1), 47-70.

European Commission (2011). Horizon 2020, http://ec.europa.eu/research/horizon2020/ [Accessed: July 23, 2014].

Felt, Ulrike (Ed.) (2009). Knowing and living in academic research. Convergence and heterogeneity in research cultures in the European Context. Prague: Institute of Sociology of the Academy of Sciences of the Czech Republic. 
Felt, Ulrike (2013). Kollaterale Zukünfte: Zu den (An)Ordnungen von Morgen. Paper presented at the conference Zukunftsexpertise. Zur Generierung, Legitimierung, Verwendung und Anerkennung von Zukunftswissen, Bielefeld, Germany, January 25, 2013.

Felt, Ulrike; Fochler, Maximilian \& Strassnig, Michael (2010). Experimente partizipativer ELSAForschung. Eine methodenpolitische Reflexion. In Erich Grießler \& Harald Rohracher (Eds.), Genomforschung - Politik - Gesellschaft. Perspektiven auf ethische, rechtliche und soziale Aspekte der Genomforschung (pp.33-67). Wiesbaden: VS Verlag.

Ferlie, Ewan; Musselin, Christine \& Andresani, Gianluca (2008). The steering of higher education systems: A public management perspective. Higher Education, 56(3), 325-348.

Fochler, Maximilian (2010). Responsibility on the move. Societal responsiveness in shifting epistemic living spaces in the life sciences. Paper presented at the Conference Risky entanglements? Contemporary research cultures imagined and practised, Vienna, Austria, June 11, 2010.

Fochler, Maximilian, Felt, Ulrike \& Müller, Ruth (2014/Forthcoming). For what it's worth. Academic lives, valuation practices and knowledge production in the life sciences. Manuscript submitted to the American Journal of Sociology.

Foucault, Michel (2004). Geschichte der Gouvernementalität II. Die Geburt der Biopolitik. Vorlesung am College de France 1978-1979. Frankfurt/M.: Suhrkamp.

Garforth, Lisa \& Cervinková, Alice (2009). Times and trajectories in academic knowledge production. In Ulrike Felt (Ed.), Knowing and living in academic research. Convergence and heterogeneity in research cultures in the European Context (pp.169-224). Prague: Institute of Sociology of the Academy of Sciences of the Czech Republic.

Hassard, John (1991). Aspects of time in organization. Human Relations, 44(2), 105-125.

Jacob, Merle \& Hellström, Tomas (Eds.) (2000). The future of knowledge production in the academy. Buckingham: Open University Press.

Koselleck Reinhart (1985). Futures past: On the semantics of historical time. Cambridge, MA: MIT Press.

Law, John (2011). Collateral realities. In Fernando Dominguez Rubio \& Patrick Baert (Eds.), The politics of knowledge (pp.156-178). London: Routledge,.

Lübbe, Hermann (1998). Gegenwartsschrumpfung, In Klaus Backhaus \& Holger Bonus (Eds.), Die Beschleunigungsfalle oder der Triumph der Schildkröte (pp.129-164). Stuttgart: Schäffer/Pöschel.

McCabe, Daniel (2012). The slow science movement. University Affairs Magazine, December 5 2012, http://www.universityaffairs.ca/the-slow-science-movement.aspx [Accessed: September 19, 2014].

Martell, Luke (2014). The slow university: Inequality, power and alternatives. Forum Qualitative Sozialforschung / Forum: Qualitative Social Research, 15(3), Art. 10, http://nbn-resolving.de/urn:nbn:de:0114-fqs1403102.

Mendick, Heather (2014). Social class, gender and the pace of academic life: What kind of solution is slow?. Forum Qualitative Sozialforschung / Forum: Qualitative Social Research, 15(3), Art. 7, http://nbn-resolving.de/urn:nbn:de:0114-fqs140374.

Müller, Ruth (2012). Collaborating in life science research groups: The question of authorship. Higher Education Policy, 25(3), 289-311.

Müller, Ruth (2014) Postdoctoral life scientists and supervision work in the contemporary university: A case study of changes in the cultural norms of science. Minerva, 52(3), 329-349.

Müller, Ruth \& Kenney, Martha (2014). Agential conversations. On interviewing life scientists and the politics of mundane research practices. Science as Culture, 23(4), 537-559.

O'Neill, Maggie (2014a). The SLOW University-Work, time and well being. Discover Society, June 3 2014, http://www.discoversociety.org/2014/06/03/the-slow-university-work-time-and-well-being/ [Accessed: July 23, 2014].

O'Neill, Maggie (2014b). The slow university: Work, time and well-being. Forum Qualitative Sozialforschung / Forum: Qualitative Social Research, 15(3), Art. 14, http://nbn-resolving.de/urn:nbn:de:0114-fqs1403146.

Osborne, Thomas (2003). Against "creativity": A philistine rant. Economy and Society, 32(4), 507525. 
Pain, Elisabeth (2014). An emerging global picture of early-career scientists. Science Careers, January 27,

http://sciencecareers.sciencemag.org/career_magazine/previous_issues/articles/2014_01_27/care dit.a1400023 [Accessed: July 23, 2014].

Power, Michael (1997). From risk society to audit society. Soziale Systeme, 3(1), 3-21.

Rosa, Hartmut (2003). Social acceleration: Ethical and political consequences of a de-synchronized highspeed society. Constellations, 10(1), 3-33.

Rosa, Hartmut (2005). Beschleunigung. Die Veränderung der Zeitstrukturen in der Moderne. Frankfurt/M.: Suhrkamp.

Russo, Eugene (2003). Victims of success. Nature, 422(6929), 354-355.

Scott, James C. (1998). Seeing like a state: How certain schemes to improve the human condition have failed. New Haven, CT: Yale University Press.

Sigl, Lisa (2012). Embodied anxiety. On experiences of living and coping with (conditions of) precarity in research cultures of the academic life sciences. Doctoral Thesis, Department of Science and Technology Studies, University of Vienna, Austria.

Slaughter, Sheila \& Leslie, Larry L. (1997). Academic capitalism. Baltimore, MD: Johns Hopkins University Press.

Star, Susan Leigh (Ed.) (1995). Ecologies of knowledge: Work and politics in science and technology. Albany, NY: State of New York University Press.

Strathern, Marylin (Ed.) (2000). Audit cultures. Anthropological studies in accountability, ethics and the academy. London: Routledge.

Strauss, Anselm L. \& Corbin, Juliet M. (1998). Basics of qualitative research. Techniques and procedures for developing grounded theory (2nd ed.). London: Sage.

Vostal, Filip (2014). Academic life in the fast lane: The experience of time and speed in British academia. Time and Society, online early January 20.

Ylijoki, Oili-Helena \& Mäntylä, Hans (2003). Conflicting time perspectives in academic work. Time \& Society, 12(1), 55-78.

\section{Author}

Ruth MÜLLER is a postdoctoral researcher at the Research Policy Group, Lund University, Sweden. She has earned her PhD in 2012 from the Department of Science and Technology Studies, University of Vienna, Austria. Her work has been exploring how academic career rationales shape the epistemic and social practices of junior researchers in the life sciences, and more recently the climate sciences. She has been engaging with concepts such as slow science since 2010, when she co-organized an international workshop on the topic at the Science \& Justice Research Centre, University of California Santa Cruz, USA, where she was a visiting scholar at the time.

Contact:

Ruth Müller

Department of Business Administration

Research Policy Group

Box 7080, SE-22007 Lund, Sweden

E-mail: ruth.mueller@fek.lu.se

URL: https://lu.academia.edu/RuthMüller

\section{Citation}

Müller, Ruth (2014). Racing for What? Anticipation and Acceleration in the Work and Career Practices of Academic Life Science Postdocs [43 paragraphs]. Forum Qualitative Sozialforschung / Forum: Qualitative Social Research, 15(3), Art. 15, http://nbn-resolving.de/urn:nbn:de:0114-fqs1403150. 